\title{
Carboxyhemoglobinemia and Methemoglobinemia in an Atypical Case of Salicylate Toxicity: A Potentially Hidden Association
}

\author{
Haig Aintablian* and Sami Kabbara \\ University of Arizona, College of Medicine, Phoenix, AZ 85004, United States.
}

\begin{abstract}
We report an atypical case of salicylate toxicity in a child without a reported exposure to aspirin, who presented with coexisting methemoglobinemia and carboxyhemoglobinemia, and provide mechanistic theories as to the potential pathway by which salicylates can lead to such dyshemoglobinemias. The patient, a 17-month old male, presented to the hospital $10 \mathrm{~h}$ after six episodes of vomiting, tachypnea and hyperpnea. Laboratory values showed a mixed respiratory alkalosis and metabolic acidosis; however, the parent's denial of aspirin exposure, coupled with laboratory results indicating carboxyhemoglobinemia, methemoglobinemia and neutrophilic leukocytosis, disguised a toxic salicylate level of $51.1 \mathrm{mg} / \mathrm{dL}$. We searched the PubMed database for sources of salicylate exposure using the terms: "salicylate exposure", "salicylate toxicity", "sources", and an association of salicylates with carboxyhemoglobinemia methemoglobinemia using those three terms. Furthermore, Google Scholar and PubMed were used to search for biochemical literature explaining the association of salicylates with red blood cell oxidation, methemoglobin and carbon monoxide formation. We discovered that the mechanism by which high dose salicylates lead to carboxyhemoglobinemia and methemoglobinemia had not been previously described. We propose that salicylates in high doses can induce a methemoglobinemia through increased vascular release of nitric oxide through induction of IL-1 $\beta$ and carboxyhemoglobinemia via lipid peroxidation, leading to the release of carbon monoxide.
\end{abstract}

Introduction

Despite various measures taken to reduce unnecessary salicylate exposure, salicylate toxicity remains prevalent amongst various age groups. In 2013, more than 33,000 cases of salicylate exposure were reported to the national poison database. As a result, 7,000 cases required treatment and unfortunately 29 deaths ensued. ${ }^{1}$ Aspirin is not the only source of salicylate and various other sources exist, such as certain laxatives and herbal remedies that if taken in high enough quantities can be toxic and even fatal in the pediatric population. For example, a teaspoon of oil of wintergreen, a common herb found in many Chinese herbal medications, ointments and flavoring agents, can be equivalent to 22 adult aspirin tablets. ${ }^{2}$

The pathophysiology of salicylate toxicity is very well delineated, with multiple mechanisms leading to the pathognomonic mixed respiratory alkalosis with metabolic acidosis seen in severe

Keywords: Salicylate toxicity; Methemoglobinemia; Carboxyhemoglobinemia. Abbreviations: IL, interleukin; NO, nitric oxide; WBC, white blood cell. Received: April 27, 2017; Revised: July 31, 2017; Accepted: August 15, 2017

${ }^{*}$ Correspondence to: Haig Aintablian, 3301 Deer Creek Ln, Glendale, CA 91208, United States. Tel: 818-455-5246, E-mail: Haig@Aintablian.com

How to cite this article: Aintablian $\mathrm{H}$, Kabbara S. Carboxyhemoglobinemia and Methemoglobinemia in an Atypical Case of Salicylate Toxicity: A Potentially Hidden Association. Exploratory Research and Hypothesis in Medicine 2017;2(3):72-76. doi: 10.14218/ERHM.2017.00009. salicylate toxicities. ${ }^{3}$ However, while the pathophysiology of salicylate toxicity on acid-base balance is well-studied, the association with carboxyhemoglobinemia and methemoglobinemia is not well documented in the literature. We present a literature review and proposed mechanism of salicylate's interaction with interleukin (IL)-1 $\beta$ and lipid peroxidation to form carbon monoxide and nitrates, which theoretically can induce carboxyhemoglobin and methemoglobin in vivo. This review is centered around a case of a toddler who presented with severe salicylate toxicity, who presented with elevated levels of carboxyhemoglobin $(1.1 \mathrm{~g} / \mathrm{dL})$ and methemoglobin $(1.3 \mathrm{~g} / \mathrm{dL})$ and who, despite having no exposure to aspirin, had a toxic salicylate level $(51.1 \mathrm{mg} / \mathrm{dL})$.

\section{Case report}

The patient was a 17-month-old, fully vaccinated, Hispanic male, who had been transferred to a pediatric hospital with the chief complaint of difficulty breathing and dehydration. He had no significant past medical history. The patient's symptoms had begun with an insidious onset of vomiting episodes at night. He was afebrile, and had non-bilious emesis 6 times before presenting for medical evaluation at an adult hospital at $10 \mathrm{~h}$ after symptom onset.

At the time of initial medical evaluation, the patient was normothermic $\left(36.8{ }^{\circ} \mathrm{C}\right)$, had a heart rate of 130 , respiratory rate of 28 , and decreased urine output. He was given $3,200 \mathrm{~mL}$ boluses 
Salicylate Toxicity

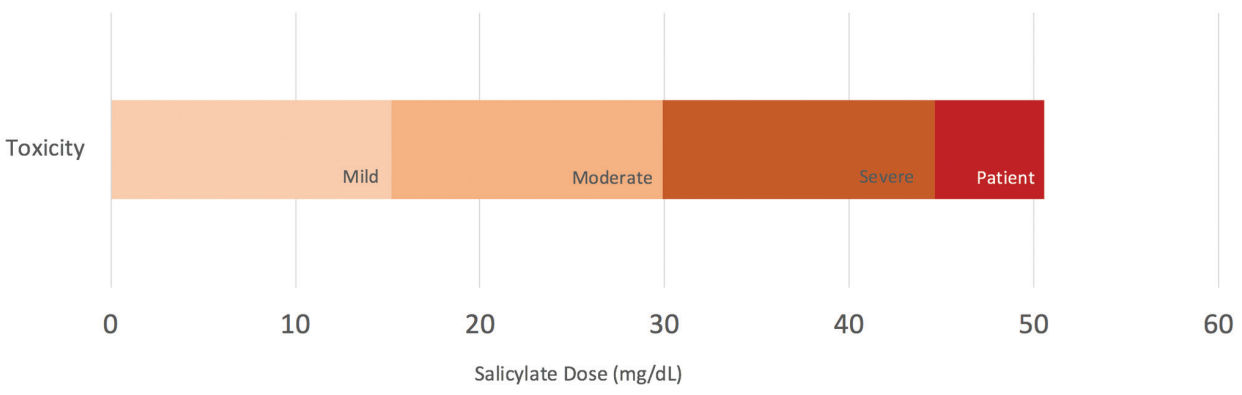

Fig. 1. Visual representation of salicylate toxicity doses and the salicylate dose of the patient reported.

of normal saline, as well as Tylenol. His laboratory analysis revealed a white blood cell (WBC) count of 15,600 , with $65 \%$ neutrophils, platelet count of 524,000 , bicarbonate of 15 , and anion gap of 18. Blood urea nitrogen, creatinine and electrolyte levels were all within normal limits; lactic acid level was 1.1 , and results of urinalysis were unremarkable. The patient was transferred to the pediatric emergency department for more advanced care.

At the time of admission to pediatric care, the patient's temperature was $36.8^{\circ} \mathrm{C}$, heart rate was 146 , respiratory rate was 32 with an oxygen saturation of $99 \%$, and blood pressure was $95 / 47$. On exam, he had tachypnea and hyperpnea, but had had no more vomiting episodes. His labs revealed a WBC count of 19,300 , with $74 \%$ neutrophils, an absolute neutrophil count of $14.4 \mathrm{~K} / \mu \mathrm{L}$ and a platelet count of 443,000 . Venous blood gas analysis showed a $\mathrm{pH}$ of 7.36, $\mathrm{pCO}_{2}$ of $17 \mathrm{mmHg}$, bicarbonate of $9 \mathrm{mmoL} / \mathrm{L}$, carboxyhemoglobin of $1.1 \mathrm{~g} / \mathrm{dL}(0.09-0.30 \mathrm{~g} / \mathrm{dL})$ or $7.7 \%$, methemoglobin of $1.3 \mathrm{~g} / \mathrm{dL}$ $(0.05-0.15 \mathrm{~g} / \mathrm{dL})$ or $9.1 \%$, and a base deficit of $15.5 \mathrm{mmol} / \mathrm{L}$. Carboxyhemoglobin and methemoglobin levels were analyzed per the pediatric hospital protocol when arterial blood gases were drawn. His electrolytes showed further abnormalities with an ionized calcium of $7.3 \mathrm{mEq} / \mathrm{L}$, sodium of $141 \mathrm{mEq} / \mathrm{L}$, potassium of $3.0 \mathrm{mEq} / \mathrm{L}$, and chloride of $119 \mathrm{mEq} / \mathrm{L}$. Glucose was $68 \mathrm{mg} / \mathrm{dL}$. Blood culture was negative. Chest X-ray findings were consistent with reactive airway disease, instead of a viral process, and respiratory polymerase chain reaction study was positive only for Rhinovirus.

On initial presentation, the patient's mother had denied that the patient had any cough, runny nose, sick contacts, travel history, or diarrhea. After further questioning regarding accidental ingestions, she stated that the medications were impossible for him to gain access, and that they had checked to make sure before they brought him to the hospital. His blood gases and acid-base disturbance (mixed respiratory alkalosis and metabolic acidosis) strongly suggested ingestion of salicylate or iron supplements. Given these findings, the patient was subsequently screened for salicylate toxicity, which showed toxic salicylate levels of $51.1 \mathrm{mg} / \mathrm{dL}$ (Fig. 1).

The patient was then admitted to the intensive care unit and started on a bicarbonate drip to remove the salicylate from the blood stream via ion trapping in the urine. The patient made a full recovery and was discharged 3 days later. Appropriate follow up showed a full recovery.

\section{Discussion}

\section{Salicylate toxicity mechanism of action}

Salicylate toxicity leads to a multifaceted change in the physiolog- ic acid-base balance. Salicylates stimulate the brain's respiratory centers in the medulla, which leads to hyperpnea, tachypnea and resultant respiratory alkalosis. Early signs of toxicity also include vomiting through direct stimulation of chemoreceptor trigger zone in the medulla, in addition to direct irritation of the gastric mucosa and decreased production of prostaglandins, which have protective properties for the mucosal barriers. Dehydration from fluid losses and sinus tachycardia can also be present. Furthermore, patients typically suffer from hyperthermia as a result of decoupling of the oxidative phosphorylation. ${ }^{4}$ Metabolic derangements, such as inhibition of the Kreb's cycle, contribute to eventual metabolic acidosis. The culmination of these interactions leads to the pathognomonic mixed respiratory alkalosis with metabolic acidosis seen in severe salicylate toxicities.

\section{Methemoglobin and carboxyhemoglobin toxicity levels}

The levels at which increasing salicylate doses become toxic are well described for both adults and infants, but not as extensively for the age group in between. Our patient was a toddler, with an age of 17 months, falling in between the bimodal distribution of ages that the literature covers. According to a report by Sulotto et al.,${ }^{5}$ mean \pm SD carboxyhemoglobin values amongst adults were $3.25 \pm 1.45 \%$ in smokers and $1.34 \pm 0.8 \%$ in non-smokers, with a wide variability in both subgroups, particularly among the smokers.

In infants and newborns, carboxyhemoglobin levels vary by multiple factors. One study dating back to 1962 by Oski et al. ${ }^{6}$ found that normal term infants had a mean carboxyhemoglobin concentration of $0.42 \%$. Infants with $\mathrm{Rh}$ incompatibility, on the other hand, had elevations ranging from $2.6 \%$ to $11.9 \%$. More recent studies since Oski's publication have reported levels of $2.38 \%$ with a standard deviation of $0.35 \%$ in normal term infants, ${ }^{7}$ and an elevation to levels of $3.64 \pm 0.83 \%$ in patients with jaundice due to hemolytic disease, sharing a similar conclusion of elevated carboxyhemoglobin in infants undergoing hemolysis, albeit with a higher mean value in the general population of Xiu-Hong et al.'s study compared to Oski et al.'s study.

Methemoglobin levels amongst the general population are normally $0.81 \%$ with a SD of $0.37 \%$ amongst adults, and are influenced by the country of inhabitants and smoking status. The reported levels are lowest in non-smoking populations $(0.66 \pm$ $0.38 \%)$ and increase with moderate smoking $(0.71 \pm 0.40 \%) .5$ The literature on children tend to attribute a higher basal level of methemoglobin compared to their adult counterparts. Retchetzki et al. ${ }^{8}$ found that in 6- to 10-year-old children, methemoglobin levels had a mean of 4.61 with a range between 3.61 and 6.44 . 


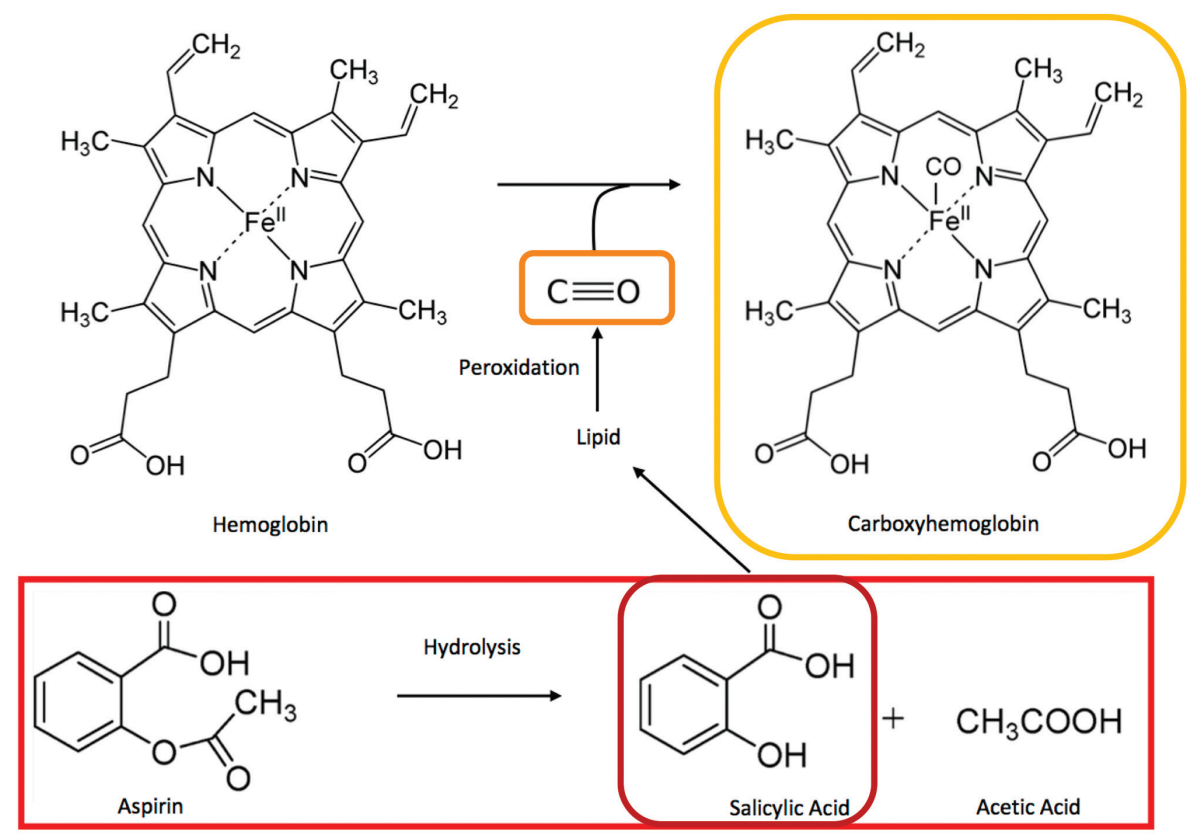

Fig. 2. Proposed mechanism of high-dose salicylate induction of carboxyhemoglobinemia.

Our patient had a carboxyhemoglobin of $1.1 \mathrm{~g} / \mathrm{dL}(0.09-0.30 \mathrm{~g} /$ $\mathrm{dL})$ or $7.7 \%$ and methemoglobin of $1.3 \mathrm{~g} / \mathrm{dL}(0.05-0.15 \mathrm{~g} / \mathrm{dL})$ or $9.1 \%$, both highly elevated regardless of age group. Although we have no direct evidence of causality, we have theorized potential mechanisms by which severe salicylate toxicity can induce methemoglobinemia and carboxyhemoglobinemia.

\section{Salicylate toxicity and carboxyhemoglobinemia}

The association of salicylates with carboxyhemoglobin is not clearly delineated. While a new class of NSAIDs with a salicylate backbone derived from aspirin, or acetylsalicylic acid, has been implicated in the production of carbon monoxide to deliver toxic $\mathrm{CO}$ to malignant mesothelioma cells, very little other literature is found that directly links salicylates to carboxyhemoglobin elevation. ${ }^{\text {? }}$

In rats, pretreatment with acetylsalicylic acid or sodium salicylate stimulates the metabolism of dichloromethane to carbon monoxide, measured by an increase in carboxyhemoglobin levels in the blood. This is thought to be attributed to a mechanism between salicylates and cytochrome $2 \mathrm{E} 1 .^{10}$

Regarding the salicylate levels in our patient, many mechanisms may be at play in his elevated carboxyhemoglobin level. Aside from the proposed cytochrome 2E1 association, studies have shown that at high concentration salicylates are capable of peroxidizing lipids. ${ }^{11}$ This peroxidation is linked to the production of carbon monoxide. ${ }^{3}$ We propose that as carbon monoxide concentrations increase due to lipid peroxidation, a byproduct of salicylate poisoning, a carboxyhemoglobinemia can begin to form (Fig. 2).

\section{Salicylate toxicity and methemoglobinemia}

The link between salicylates and methemoglobinemia is also elusive in the literature. However, recent studies in rats have demon- strated that biochemical pathways exist in vascular smooth muscle cells that are triggered by salicylate-based drugs to up-regulate the synthesis of nitric oxide (NO). ${ }^{12}$ This mechanism is believed to involve cytokines such as IL-1 $\beta$ (Fig. 3). ${ }^{13}$

$\mathrm{NO}$ is, in turn, an important substrate for conversion of hemoglobin to methemoglobin. ${ }^{14}$ This postulation is supported by numerous incidents where life-threatening methemoglobinemia has occurred post-NO therapy. ${ }^{15-17}$ This NO-induced methemoglobinemia phenomenon could be also explained in that the NO production requires the conversion of NADPH to NADP+, in which the former is required by the NADPH-dependent methemoglobin reductase for the conversion of methemoglobin to hemoglobin. ${ }^{18}$ Hence, extensive production of NO could reduce the levels of NADPH low enough to impair the proper activity of methemoglobin reductase.

Moreover, various drugs that share very chemical structure similar to salicylic acid have already been reported to cause methemoglobinemia. ${ }^{19-21}$ For example, the two drugs that are shown to cause methemoglobinemia, aminosalicylic acid and mesalazine, both have the same structure as salicylic acid, except for an extra amine group on the $4^{\prime}$ and $5^{\prime}$ carbon, respectively (Fig. 4). Therefore, the general structure of 2-hydroxybenzoic acid (salicylic acid) could be the culprit functional group in causing methemoglobinemia.

\section{Conclusions}

Mechanistically, high-dose salicylates leading to carboxyhemoglobinemia and methemoglobinemia in a patient with severe salicylate toxicity has not been previously described. Although we do not have direct evidence of causality in this case, we have described a novel mechanism for how salicylates in toxic doses can potentially induce carboxyhemoglobinemia and methemoglobinemia. Toxic salicylate doses have been shown to induce IL-1 $\beta$, a potent inducer of vasoconstriction, which results in the release of 


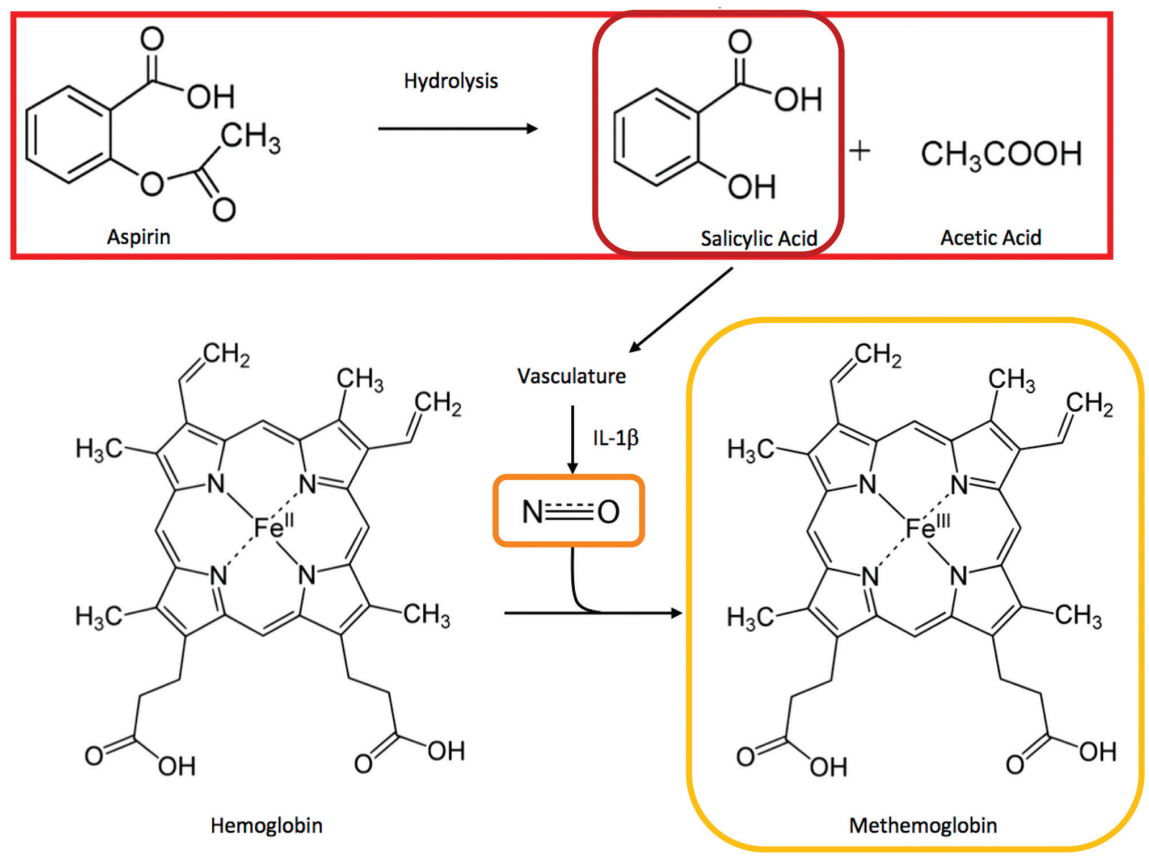

Fig. 3. Proposed mechanism of high-dose salicylate induction of methemoglobinemia.
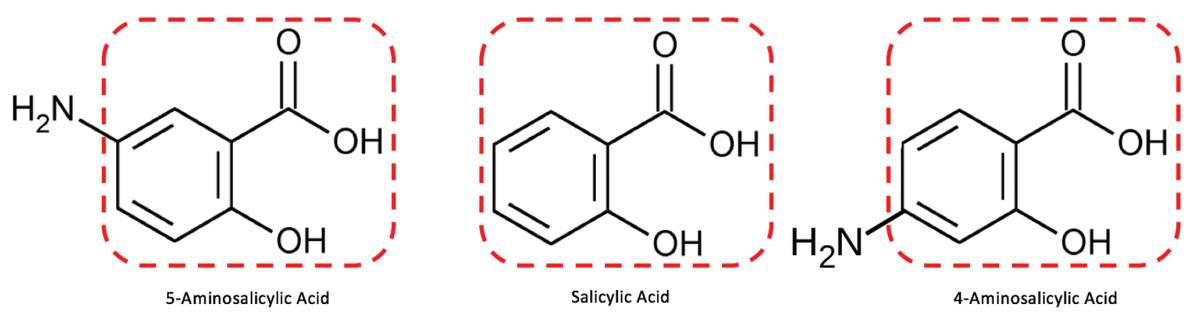

Fig. 4. Comparison of functional groups of various salicylates implicated in methemoglobinemia.

NO from the vasculature, which serves as a molecular inducer of methemoglobinemia. ${ }^{13,14}$ Furthermore, regarding carboxyhemoglobinemia, high-dose salicylates lead to the peroxidation of lipids, causing release of toxic carbon monoxide, a potent inducer of carboxyhemoglobinemia.,"11 Salicylate toxicity results in many physiological changes, the most pathognomonic being a mixed respiratory alkalosis and anion gap metabolic acidosis. A rare finding, such as carboxyhemoglobinemia and methemoglobinemia may be clinically confusing and potentially disguise a severe salicylate toxicity to clinicians, which we hope can be avoided by those who read this case.

\section{Conflict of interest}

The authors have no conflict of interests related to this publication.

\section{Author contributions}

Analysis and interpretation of data (HKA), primary manuscript writing (HKA), critical revision (HKA), statistical analysis (HKA), illustration (HKA), technical or material support (HKA), second- ary manuscript writing and technical or material support (SK).

\section{References}

[1] Mowry JB, Spyker DA, Cantilena LR Jr, McMillan N, Ford M. 2013 annual report of the American association of poison control centers' National poison data system (NPDS): 31st annual report. Clin Toxicol (Phila) 2014;52(10):1032-1283. doi:10.3109/15563650.2014.98739 7.

[2] Botma M, Colquhoun-Flannery W, Leighton S. Laryngeal oedema caused by accidental ingestion of Oil of Wintergreen. Int J Pediatr Otorhinolaryngol 2001;58(3):229-232. doi:10.1016/S01655876(01)00453-0.

[3] Temple AR. Pathophysiology of aspirin overdosage toxicity, with implications for management. Pediatrics 1978;62(5 Pt 2 Suppl):873-876.

[4] Miyahara JT, Karler R. Effect of salicylate on oxidative phosphorylation and respiration of mitochondrial fragments. Biochem J 1965;97(1):194-198. doi:10.1042/bj0970194.

[5] Sulotto F, Romano C, Insana A, Carrubba Cacciola M, Cerutti A. Normal values of carboxyhemoglobinemia and methemoglobinemia in a sample of conscripts. Med Lav 1994;85(4):289-298.

[6] Oski FA, Altman AA. Carboxyhemoglobin levels in hemolytic disease of the newborn. J Pediatr 1962;61(5):709-713. doi:10.1016/\$00223476(62)80342-4.

[7] Pu XH, Li Q, Guo XQ, An T, Qiu M, Wang XQ. Value of carboxyhemo- 
Explor Res Hypothesis Med

globin in the diagnosis of neonatal jaundice. Zhongguo Dang Dai Er Ke Za Zhi 2006;8(4):291-294.

[8] Rechetzki KF, Henneberg R, da Silva PH, do Nascimento AJ. Reference values for methemoglobin concentrations in children. Rev Bras Hematol Hemoter 2012;34(1):14-16. doi:10.5581/1516-8484.20120007.

[9] Zanellato I, Bonarrigo I, Ravera M, Gabano E, Gust R, Osella D. The hexacarbonyldicobalt derivative of aspirin acts as a CO-releasing NSAID on malignant mesothelioma cells. Metallomics 2013;5(12):16041613. doi:10.1039/c3mt00117b.

[10] Pankow D, Damme B, Schrör K. Acetylsalicylic acid-inducer of cytochrome P-450 2E1. Arch Toxicol 1994;68(4):261-265.

[11] Saha A, De AU, Sengupta C. Effect of aspirin on blood-lipid interaction and lipid peroxidation phenomena in relation to partition coefficient and biological activity. Indian J Exp Biol 2000;38(9):912-915.

[12] Shimpo M, Ikeda U, Maeda Y, Ohya KI, Murakami Y, Shimada K. Effects of Aspirin-Like Drugs on Nitric Oxide Synthesis in Rat Vascular Smooth Muscle Cells. Hypertension 2000;35(5):1085-1091. doi:10.1161/01. HYP.35.5.1085.

[13] Kanno K, Hirata Y, Imai T, Iwashina M, Marumo F. Regulation of inducible nitric oxide synthase gene by interleukin-1 beta in rat vascular endothelial cells. Am J Physiol 1994;267(6 Pt 2):H2318-H2324.

[14] Recchia FA, Vogel TR, Hintze TH. NO metabolites accumulate in erythrocytes in proportion to carbon dioxide and bicarbonate concentration. Am J Physiol Heart Circ Physiol 2000;279(2):H852-H856.
Aintablian H. et al: Dyshemoglobinemias due to salicylate toxicity

[15] Sinisterra S, Miravet E, Alfonso I, Soliz A, Papazian O. Methemoglobinemia in an infant receiving nitric oxide after the use of eutectic mixture of local anesthetic. J Pediatr 2002;141(2):285-286. doi:10.1067/mpd.2002.125732.

[16] Syed AU, Jelly AE, Algebaly AA, Altoonisi MM, Shatoory AE. Methemoglobinemia due to nitric oxide therapy in a child after cardiac surgery. Asian Cardiovasc Thorac Ann 2013;21(3):345-347. doi:10.1177/0218492312454276.

[17] Taylor MB, et al. Methemoglobinemia: Toxicity of inhaled nitric oxide therapy. Pediatr Crit Care Med 2001;2(1):99-101.

[18] Hultquist DE, Xu F, Quandt KS, Shlafer M, Mack CP, Till GO, et al. Evidence that NADPH-dependent methemoglobin reductase and administered riboflavin protect tissues from oxidative injury. Am J Hematol 1993;42(1):13-18. doi:10.1002/ajh.2830420105.

[19] Druez A, Rahier JF, Hébuterne X. Methaemoglobinaemia and renal failure following mesalazine for treatment of inflammatory bowel disease. J Crohns Colitis 2014;8(8):900-901. doi:10.1016/j. crohns.2013.12.025.

[20] Munroe WD, Lawson WJ, Holcomb TH. Hemolytic Anemia Due To Aminosalicylic Acid: Anemia With Methemoglobinemia. Am J Dis Child 1964;108(4):425-429. doi:10.1001/archpedi.1964.02090010427014.

[21] Simmel ER. Methemoglobinemia Due to Aminosalicylic Acid (PAS) 1. Am Rev Respir Dis 1962;85(1):105-109. 